\title{
Peningkatan Kinerja Karyawan Pada Dealer Honda Auto Serang Banten Melalui Employee Engagement dan Komunikasi Internal
}

\author{
Nafiudin \\ Fakultas Ekonomi dan Bisnis, Universitas Serang Raya \\ Email: nafiuddin08@gmail.com
}

\begin{abstract}
Abstrak: Penelitian ini bertujuan untuk mengetahui pengaruh Employee Engagement dan Komunikasi Internal terhadap Kinerja Karyawan Dealer Honda Auto Serang Banten. Sampel penelitian menggunakan rumus slovin sebesar 71 karyawan dengan populasi sebesar 250 karyawan. Untuk jenis penelitian adalah kuantitatif. Metode pengumpulan data adalah kuesioner/angket. Teknik analisis data adalah Uji Validitas, Uji Reliabilitas, Uji Normalitas, Uji Multikolineraitas, Uji Heterokedastisitas, Analisis Regresi Linier Berganda, Koefisien Determinansi, Uji T, dan Uji F. Penelitian ini secara parsial Employee Engagement berpengaruh signifikan terhadap Kinerja Karyawan. Secara parsial Komunikasi Internal berpengaruh signifikan terhadap Kinerja Karyawan. Dan secara simultan Employee Engagement dan Komunikasi Internal berpengaruh signifikan terhadap Kinerja Karyawan. Dengan koefisien determinansi berganda $\left(\mathrm{R}^{2}\right)$ Adjusted $R$ Square sebesar 0,627.
\end{abstract}

Kata Kunci : Employee Engagement, Komunikasi Internal, Kinerja Karyawan

\begin{abstract}
This study aims to determine the influence Employee Engagement and Internal Communication on Employee Performance. The sample of this study used the Slovin formula of 71 employees with a poulation of 250 employees. For this type of research is quantitative. Data collection method is a questionnaire. Data analysis techniques are Validity Test, Reliability Test, Normality Test, Multicollinearity Test, Heterokedasticity Test, Multiple Linear Regression Analysis, Coefficient of Determinantion, T Test, F Test. This research partially Employee Engagement significant effect on Employee Performance. Partially Internal Communication has a significant effect on Employee Performance. And simultaneously Employee Engagement and Internal Communication significant effect on Employee Performance. With multiple determinantion coefficients $\left(\mathrm{R}^{2}\right)$ Adjusted R Square of 0,627 .
\end{abstract}

Keywords : Employee Engagement, Internal Communication, Employee Performance 


\section{PENDAHULUAN}

Pada berbagai bidang khususnya kehidupan berorganisasi, faktor manusia merupakan masalah utama disetiap kegiatan yang ada didalamnya. Organisasi merupakan sekumpulan orang-orang yang memiliki keterkaitan satu sama lain dalam rangka mencapai tujuan organisasi dan penentu pencapaian organisasi diprakarsai dan ditentukan oleh anggota organisasi tersebut.

Ketercapaian tujuan organisasi bisa diupayakan melalui peningkatan kinerja karyawan, sedangkan kinerja karyawan merupakan hasil karyawan berdasarkan standar kerja yang ditentukan oleh pihak organisasi. Dalam dunia persaingan bisnis yang penuh dengan tidak kepastian, maka peningkatan kinerja merupakan kunci berlangsungan dari bisnis perusahaan tersebut. Oleh karena itu usaha meningkatkan prestasi kerja karyawan menjadi hal yang paling serius bagi perusahaan, sebab keberhasilan untuk meraih tujuan dan keberlangsungan hidup perusahaan tergantung pada kinerja sumberdaya manusia yang ada didalamnya baik dari dimensi kulaitas maupun kuantitas.

Setiap Perusahan mengharapkan Kinerja karyawan yang tinggi. Semakin banyak karyawan yang mempunyai kinerja tinggi, maka produktivitas perusahaan secara keseluruhan akan meningkat sehingga perusahaan akan dapat bertahan dalam persaingan global. Karyawan dituntut untuk mampu menyelesaikan tugas dan tanggung jawabnya secara efektif dan efisien. Kinerja karyawan dapat dilihat melalui survey kepuasan konsumen, berkurangnya jumlah keluhan dan tercapainya target yang optimal, ketika jumlah kepuasan konsumen meningkat, maka itu salah satu gejala bahwa kinerja karyawan mengalami permasalahan.

Dealer Honda Auto Serang Banten adalah cabang dealer mobil honda Indonesia di provinsi Banten dan merupakan dealer mobil serang terbaik yang menawarkan harga jual mobil honda serang termurah di kota Serang dan Cilegon. Dealer Honda Auto Serang Banten adalah satu-satunya Dealer Resmi Mobil Honda. Dengan Pelayanan 3S (Sales, Service, Spare Part) Honda Auto Serang Banten berkomitmen untuk memberikan pelayanan yang terbaik dalam segala hal. Fasilitas yang tersedia meliputi: Waiting Room yang nyaman, Free Snack and Drink, Musholla dan Playground untuk anak-anak. Saat ini Honda Auto Serang Banten memiliki Outlet di Ciruas, Cilegon, Rangkas, dan Pandeglang.

Kinerja karyawan Dealer Honda Auto Serang Banten juga dapat diukur melalui penyelesaian tugasnya secara efektif dan efesien serta melakukan peran dan fungsinya dan itu semua terkait dengan keberhasilan suatu perusahaan.

Berdasarkan hasil angket (kuesioner) yang dilakukan pada karyawan Dealer Honda Auto Serang Banten, kondisi yang terjadi pada kinerja karyawannya ditinjau dari segi indikator kuantitas pekerjaan antara lain, kurangnya hasil kerja karyawan yang melebihi target yang diberikan oleh perusahaan. Dilihat dari indikator kemandirian pekerjaan masih ada karyawan 
yang kadang harus diberi arahan/pengawasan dari pimpinan, dan kurangnya inisiatif dalam menyelesaikan pekerjaan sendiri tanpa harus menunggu perintah dari atasan. Dan dilihat dari indikator ketepatan waktu pekerjaan masih ada karyawan yang kurang tepat waktu dalam absensi.

Menurut penelitian yang dilakukan oleh Ramadhan dan Jafar Sembiring, mengatakan bahwa employee engagement merupakan salah satu cara untuk membuat karyawan memiliki loyalitas yang tinggi, seperti pendapat Macey dan Schneider (dikutip oleh Hermawan, 2011:16) yang menyatakan bahwa employee engagement mampu mengurangi niat karyawan untuk pindah ke perusahaan lain, Karyawan yang memiliki engagement tinggi cenderung lebih memiliki kinerja yang baik karena memiliki perasaan yang positif dan tidak menjadikan pekerjaannya sebagai beban. Hal ini jelas sangat berpengaruh bagi kinerja karyawan yang dihasilkan. Keterikatan karyawan telah dianggap sebagai pengantar kesuksesan bisnis di pasar yang kompetitif seperti saat ini dan salah satu faktor penentu dalam kesuksesan organisasional.

Komunikasi yang lancar didalam organisasi dapat mendorong terjadinya kinerja. Apabila proses komunikasi dalam bekerja antar karyawan terjadi tanpa ada permasalahan yang mempengaruhinya maka hal itu akan menjadi pendorong bagi karyawan mencapai kinerja yang diharapkan perusahaan. Namun komunikasi terkadang menjadi tidak stabil dan mengakibatkan kondisi kerja menjadi buruk. Disaat itu diperlukan sosok pemimpin yang dapat mengarahkan, memotivasi, dan menjaga para karyawan agar dapat bekerja dengan baik.

Sedangkan pada komunikasi untuk menciptakan suatu kinerja yang baik dari setiap karyawannya yang mana didalamnya orang-orang saling berdialog yang menimbulkan interaksi antar personal dan melahirkan faktor kesamaan akan lebih meningkatkan keakraban diantara komunikator dan komunikan. Proses pengalihan informasi pada komunikasi antar personal selalu mengandung pengaruh tertentu.

Berdasarkan latar belakang yang telah diuraikan diatas maka penulis merasa terdorong untuk melakukan penelitian yang membahas employee engagement (keterikatan karyawan) dan komunikasi internal demi tercapainya suatu kinerja karyawan yang baik bagi perusahaan dengan judul "Pengaruh Employee Engagement dan Komunikasi Internal Terhadap Kinerja Karyawan pada Dealer Honda Auto Serang Banten".

\section{Rumusan Masalah}

Berdasarkan latar belakang masalah di atas maka rumusan masalah penilitian ini adalah sebagai berikut: 
1. Apakah employee engagement memiliki pengaruh terhadap kinerja karyawan Dealer Honda Auto Serang Banten?

2. Apakah terdapat Pengaruh komunikasi internal terhadap kinerja karyawan Dealer Honda Auto Serang Banten?

3. Apakah terdapat Pengaruh employee engagement dan komunikasi internal terhadap kinerja karyawan Dealer Honda Auto Serang Banten.

\section{Tujuan Penelitian}

Adapun tujuan penelitian ini adalah:

1. Untuk menganalisis apakah terdapat Pengaruh employee engagement terhadap kinerja karyawan Dealer Honda Auto Serang Banten dilakukan secara parsial.

2. Untuk menganalisis apakah terdapat Pengaruh komunikasi internal terhadap kinerja karyawan Dealer Honda Auto Serang Banten dilakukan secara parsial.

3. Untuk menganalisis apakah terdapat Pengaruh employee engagement dan komunikasi internal terhadap kinerja karyawan Dealer Honda Auto Serang Banten dilakukan secara simultan.

\section{LANDASAN TEORI}

\section{Employee Engagement}

Menurut Hughes dan Rog (2008), employee engagement adalah keterkaitan antara perasaan emosional dan intelektual yang tinggi dimiliki oleh karyawan terhadap pekerjaannya, organisasi, manajer, atau rekan kerja yang memberikan pengaruh dalam memberikan kontribusi yang lebih terhadap organisasi. Istilah employee engagement pertama kali diperkenalkan oleh William Khan pada tahun 1990, yang menyatakan bahwa engagement merupakan pemanfaatan diri anggota suatu organisasi untuk peran pekerjaan mereka dengan menggunakan dan mengekspresikan diri, baik secara fisik, kognitif dan emosional selama menjalankan peran mereka didalam organisasi.

Menurut Robinson, Perryman dan Hayday (2004), employee engagement adalah sikap positif individu karyawan terhadap organisasi dan nilai organisasi. Seorang karyawan yang memiliki tingkat keterikatan tinggi pada organisasi, mereka memiliki pemahaman dan kepedulian terhadap berjalannya operasional organisasi, mampu bekerja sama sama untuk meningkatkan pencapaian unit kerja/organisasi melalui kerja sama antara individu karyawan dengan manajemen. 
Berdasarkan definisi di atas bahwa Pencapaian tujuan organisasi karyawan harus memiliki sudut pandang yang positif yang menyebabkan prilaku dan sikap yang baik terhadap pekerjaan dan organisasinya dan dalam prilakunya menujukan rasa semangat, dedikasi dan keasyikan dalam bekerja, maka karyawan terebut telah memiliki rasa keterikatan dengan organisasi. Seorang karyawan yang memiliki tingkat keterikatan yang tinggi pada organisasi memiliki pemahaman dan kepedulian terhadap lingkungan organisasi, antusias dalam bekerja, mampu bekerja sama dengan karyawan lain, berbicara hal yang baik mengenai organisasi dan bekerja melebihi harapan organisasi.

\section{Tingkatan Employee Engagement}

Menurut Gallup (2004), terdapat tiga tingkatan engagement pada karyawan, yaitu sebagai berikut :

1. Engaged, Karyawan yang engaged adalah seorang pembangun (builder). Mereka selalu dan akan menunjukkan performa kerja dengan level yang tinggi. Karyawan ini bersedia menggunakan minat, bakat dan kekuatan mereka dalam bekerja setiap hari serta selalu bekerja dengan penuh gairah dan selalu mengembangkan inovasi agar perusahaan berkembang.

2. Not Engaged, Karyawan tipe ini cenderung fokus terhadap tugas yang diberikan perusahaan dibandingkan mencapai tujuan dari pekerjaan itu sendiri. Mereka selalu menunggu perintah dan cenderung merasa kontribusi mereka diabaikan.

3. Actively Disengaged, Karyawan tipe ini adalah penunggu gua (cave dweller). Mereka secara konsisten menunjukkan perlawanan pada semua aspek. Mereka hanya melihat sisi negatif pada berbagai kesempatan dan setiap harinya, tipe actively disengaged ini melemahkan apa yang dilakukan oleh pekerja yang engaged.

\section{Ciri Employee Engagement}

Menurut Schaufeli dan Bakker (2008), karyawan atau pegawai yang memiliki engagement yang tinggi memiliki ciri-ciri 3S (Say, Stay, Strive), yaitu sebagai berikut :

1. Say, Selalu berbicara positif mengenai orgaisasi dimana ia bekerja kepada rekan sekerja, calon karyawan yang potensial dan juga kepada pelanggan.

2. Stay, memiliki keinginan untuk bertahan di organisasi di tempat ia bekerja dibandingkan memilih kerja di tempat lain.

3. Strive, meyediakan waktu lebih untuk bekerja demi kemajuan organisasi. 


\section{Faktor Yang Mempengaruhi Employee Engagement}

Menurut Bakker dan Demerouti (2007), ada tiga faktor yang mempengaruhi employee engagement, yakni sebagai berikut :

1. Job Resources, Merujuk pada aspek fisik, sosial, maupun organisasional dari pekerjaan yang memungkinkan individu untuk: mengurangi tuntutan pekerjaan dan biaya psikologis maupun fisiologis yang berhubungan dengan pekerjaan tersebut, mencapai target pekerjaan, dan menstimulasi pertumbuhan, perkembangan, dan perkembangan personal.

2. Salience of Job Resources, Faktor ini merujuk pada seberapa penting atau bergunanya sumber daya pekerjaan yang dimiliki oleh individu.

3. Personal Resources

Karakteristik yang dimiliki oleh karyawan seperti kepribadian, sifat, usia, dan lain-lain. Karyawan yang engaged akan memiliki karakteristik personal yang berbeda dengan karyawan lainnya karena memiliki nilai patuh yang dominan biasanya orang teresebut cenderung penuh semangat, ramah, komunikatif serta karakterstik lainnya yaitu concientiousness yang lebih tinggi serta memiliki skor neuoriticism yang lebih rendah.

\section{Komunikasi Internal}

Istilah komunikasi dalam bahasa inggris "communication" berasal dari kata "communication" dan perkataan ini bersumber pada kata "communis". Kata communis mengandung arti sama, maksudnya sama makna. Sedangkan bentuk dari kata kerja "communication" adalah "communicare" yang artinya bermusyawarah, berunding atau berdialog. Aliran informasi pada suatu organisasi dibagi menjadi dua dimensi yakni komunikasi secara internal dan eksternal.

Komunikasi internal adalah proses penyampaian pesan-pesan yang berlangsung antara pimpinan dengan bawahan, pimpinan dengan pimpinan, maupun bawahan dengan bawahan. Muhammad (2001) bahwa komunikasi internal yaitu komunikasi yang disampaikan kepada anggota organisasi dengan kata lain penerima pesan dalam komunikasi internal adalah orang-orang berada di organisasi tersebut. Komunikasi menjadi bagian penting dalam kehidupan kerja suatu organisasi. Hal ini dapat dipahami karena komunikasi yang kurang baik mempunyai pengaruh yang luas terhadap kualitas kehidupan organisasi, misalnya konflik antar karyawan. Sebaliknya komunikasi yang baik dapat meningkatkan dan menjaga saling pengertian, kerjasama dan kepuasan kerja. Oleh karena itu, hubungan komunikasi yang tranfaran harus dibentuk dalam organisasi.

Dalam setiap organisasi, komunikasi memiliki peranan yang begitu penting. Komunikasi merupakan salah satu unsur penting dalam berbisnis, jika 
kita ibaratkan bahwa komunikasi merupakan darah sumber kehidupan dalam berbisnis dan kehidupan pribadi.

\section{Proses Komunikasi}

Pada dasarnya proses komunikasi terjadi atas dua tahap, yaitu secara primer dan sekunder. Proses komunikasi secara primer adalah proses penyampaian fikiran dan atau perasaan seseorang kepada orang lain dengan menggunakan lambang ( $\mathrm{symbol}$ ). Misalnya berupa bahasa, isyarat, gambar, warna dan sebagainya. Proses komunikasi secara sekunder adalah proses penyampaian pesan oleh seseorang kepada orang lain dengan menggunakan alat atau sarana sebagai media kedua setelah memakai lambang media. Misalnya dengan menggunakan media telepon, radio, surat, papan pengumuman dan sebagainya.

\section{Aspek-Aspek Komunikasi}

Aspek-aspek komunikasi atasan kepada bawahan yang efektif, yaitu :

1. Pemahaman, Pemahaman merupakan penerimaan yang cermat dari karyawan mengenai isi pesan yang dimaksud oleh atasan. Isi pesan tersebut dapat bersifat verbal maupun non verbal seperti memo, buku pedoman atau kebijakan. Karyawan diharapkan dapat memahami pesan yang disampaikan atasan sesuai dengan maksud atasan sehingga apa yang karyawan kerjakan tepat sasaran.

Ketepatan pemahaman karyawan terhadap tugas-tugas atau perintah yang diberikan atasan sangat penting karena akan mempengaruhi bagaimana penerapannya dan hasil kerjanya, untuk itu organisasi perlu mengambil langkah yang tepat dalam memastikan bahwa semua pegawai memiliki keahlian yang perlu untuk menerjemahkan pesan-pesan secara efektif. Semakin dekat pesan yang diterjemahkan dengan maksud komunikator maka semakin efektif komunikasi yang terjadi.

2. Perubahan Sikap, Komunikasi ditujukan untuk mempengaruhi karyawan baik dalam pendapat, sikap dan tindakan sesuai dengan yang diharapkan atasan, dalam rangka mencapai tujuan-tujuan dan nilai-nilai organisasi. Koontz et al berpendapat bahwa komunikasi dapat dijadikan sebagai sarana untuk memodifikasi perilaku dan mempengaruhi perubahan. Dengan adanya komunikasi, koordinasi dan perubahan dapat dilakukan dengan baik.

3. Hubungan Sosial Yang Baik, Komunikasi diharapkan dapat menimbulakn suatu hubungan sosial yang baik antara atasan dan bawahan dalam arti dapat menimbulkan kepercayaan antara kedua pihak, tidak terjadi kesalahpahaman, menciptakan interaksi yang baik, atasan dapat mengendalikan dan memotivasi bawahan, sedangkan bawahan pun mau untuk dikendalikan dan dimotivasi oleh atasan. 
4. Tindakan, Komunikasi dapat mendorong karyawan untuk bertindak sesuai yang dimaksud atasan, tanpa rasa keterpaksaan. Efektivitas komunikasi diukur dari tindakan nyata yang ditunjukkan oleh karyawan. Untuk dapat menimbulkan tindakan, atasan harus berhasil menanamkan pemahaman, meyakini karyawan agar mengubah sikap sesuai tujuan organisasi dan menumbuhkan hubungan yang baik dengan karyawan.

\section{Kinerja Karyawan}

Kinerja merupakan tingkat pencapaian hasil atas pelaksanaan tugas tertentu. Dalam konteks pengembangan sumber daya manusia kinerja seorang karyawan dalam sebuah perusahaan sangat dibutuhkan untuk mencapai prestasi kerja bagi karyawan itu sendiri dan juga untuk keberhasilan perusahaan.

Istilah kinerja berasal dari job performance atau actual performance (prestasi kerja atau prestasi sesungguhnya yang dicapai oleh seseorang), atau juga hasil kerja secara kualitas dan kuantitas yang ingin dicapai oleh seorang karyawan dalam melaksanakan tugasnya sesuai dengan tanggung jawab yang diberikan kepadanya (Mangkunegara 2007:67).

Berdasarkan definisi diatas bahwa kinerja merupakan suatu konsep yang strategis dalam rangka menjalin hubungan kerjasama antara pihak manajemen dengan para karyawan untuk mencapai kinerja yang baik, unsur yang paling dominan adalah sumber daya manusia, walaupun perencanaan telah tersusun dengan baik dan rapi tetapi apabila orang atau personil yang melaksanakan tidak berkualitas dengan tidak memiliki semangat kerja yang tinggi, maka perencanaan yang telah disusun tersebut akan sia-sia.

\section{Arti Penting Kinerja}

Arti penting dari kinerja adalah hasil kerja yang dapat seseorang atau sekelompok orang dalam suatu organisasi, sesuai dengan wewenang dan tanggung jawab masing-masing dalam upaya mencapai tujuan organisasi bersangkutan secara legal, tidak melanggar hukum dan sesuai dengan moral maupun etika (Sedarmayanti 2007:260).

Unit sumber daya manusia dalam suatu organisasi seharusnya berperan untuk menganalisis dan membantu memperbaiki masalah-masalah dalam pencapaian kinerja. Apa yang sesungguhnya menjadi peranan unit sumber daya manusia dalam suatu organisasi ini seharusnya tergantung pada apa yang diharapkan manajemen tingkat atas, seperti fungsi manajemen manapun, kegiatan manajemen sumber daya manusia harus dievaluasi dan direkayasa sedemikian sehingga mereka dapat memberikan kontribusi untuk kinerja yang kompetitif dari organisasi dan individu pada pekerjaan (Robbins 2003:82). 
Hasil kerja yang dicapai seorang karyawan juga haruslah dapat memberikan kontribusi yang penting bagi perusahaan yang dilihat dari segi kualitas yang dirasakan oleh perusahaan dan sangat besar manfaatnya dimasa yang akan datang.

\section{Faktor-Faktor Yang Mempengaruhi Kinerja}

Faktor-faktor yang dapat mempengaruhi pencapaian kinerja adalah faktor kemampuan (ability) dan faktor motivasi (motivation). (Mangkunegara 2007:67).

1. Faktor Kemampuan, Secara psikologis, kemampuan terdiri dari kemampuan potensi (IQ) dan kemampuan realita, artinya karyawan yang memiliki IQ yang rata-rata (IQ 110-120) dengan memadai untuk jabatannya dan terampil dalam mengerjakan pekerjaannya sehari-hari, maka ia akan lebih mudah mencapai kinerja yang diharapkan. Oleh karena itu karyawan perlu ditempatkan pada pekerjaan yang sesuai dengan keahliannya.

2. Faktor Motivasi, Motivasi terbentuk dari sikap (attitude) seorang karyawan dalam menghadapi situasi kerja. Motivasi merupakan kondisi yang menggerakan diri karyawan yang terarah untuk mencapai tujuan organisasi (tujuan kerja). Sikap mental merupakan kondisi mental yang mendorong diri karyawan untuk berusaha mencapai prestasi kerja secara maksimal. Sikap mental yang siap secara Psikofik artinya seorang karyawan harus siap mental, mampu secara fisik, memahami tujuan utama dan target kerja yang akan dicapai, mampu memanfaatkan dalam mencapai situasi kerja.

Kinerja dipengaruhi oleh faktor intrinsik yaitu personal individu dan faktor ekstrinsik yaitu kepemimpinan, sistem, tim, situasional dan konflik. Dalam (Sjafri 2007:155).

Uraian rincian faktor-faktor tersebut sebagai berikut :

1. Faktor Personal/Individual, meliputi unsur pengetahuan, keterampilan (skill), kemampuan, kepercayaan diri, motivasi dan komitmen yang dimiliki oleh tiap individu karyawan.

2. Faktor Kepemimpinan, meliputi aspek kualitas manajer dan team leader dalam memberikan dorongan, semangat, arahan dan dukungan kerja kepada karyawan.

3. Faktor Tim, meliputi kualitas dukungan dan semangat yang diberikan oleh rekan dalam satu tim, kepercayaan terhadap sesama anggota tim, kekompakkan dan keeratan anggota tim. 
4. Faktor Sistem, meliputi sistem kerja, fasilitas kerja atau infrastruktur yang diberikan oleh organisasi, proses organisasi dan kultur kinerja dalam organisasi.

5. Faktor Situasional, meliputi tekanan dan perubahan lingkungan eksternal dan internal.

Konflik, meliputi konflik dalam diri individu/konflik peran, konflik antar individu, konflik antar kelompok/organisasi.

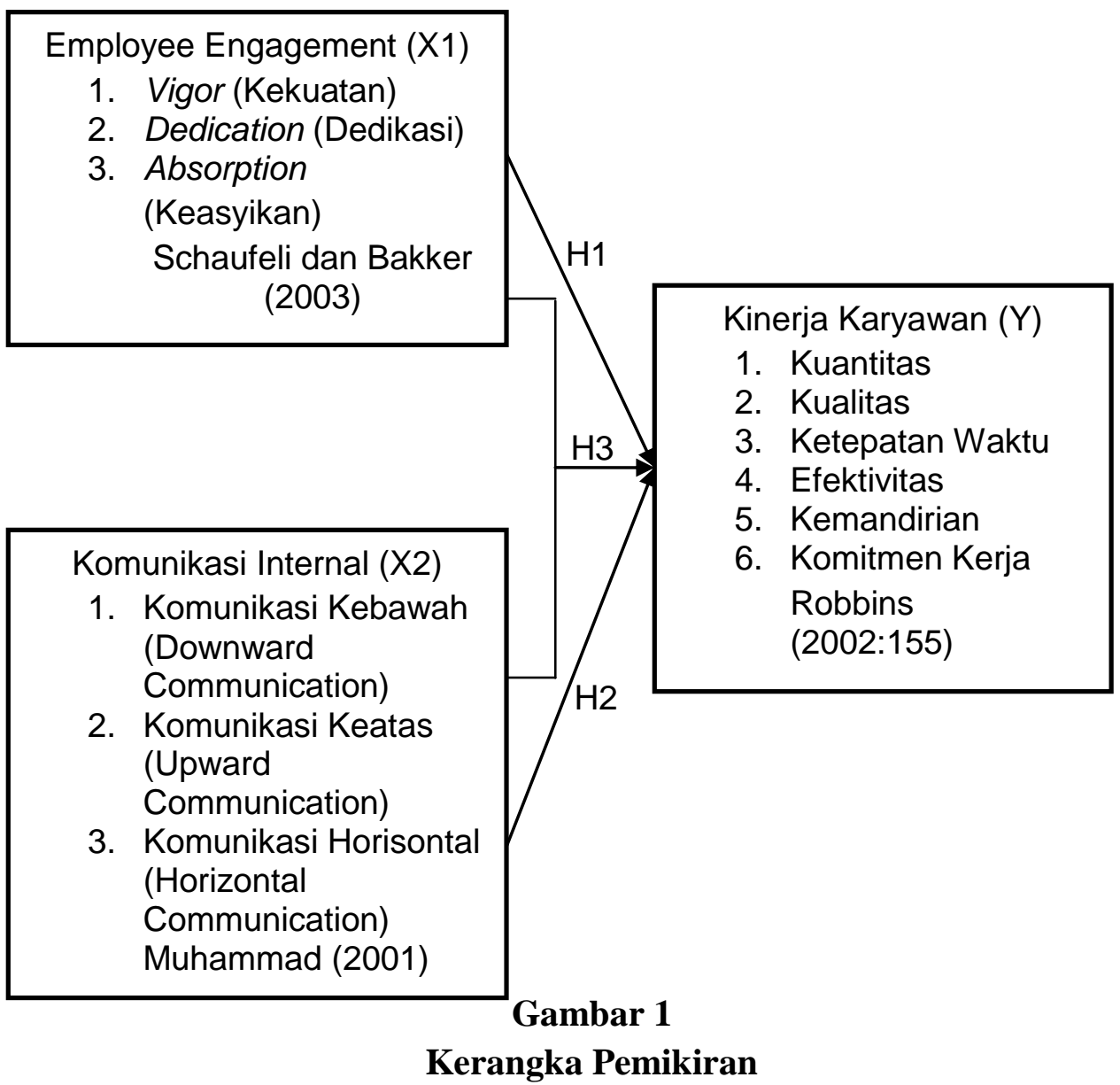

\section{Hipotesis}

Hipotesis merupakan jawaban sementara terhadap objek yang akan diteliti mengacu kerangka pemikiran yang telah dipaparkan diatas menarik dugaan sementara bahwa :

H1 : Employee engagement berpengaruh signifikan terhadap kinerja karyawan Dealer Honda Auto Serang Banten.

H2 : Komunikasi internal berpengaruh signifikan terhadap kinerja karyawan Dealer Honda Auto Serang Banten. 
H3 : Employee engagement dan komunikasi internal berpengaruh signifikan terhadap kinerja karyawan Dealer Honda Auto Serang Banten.

\section{METODE PENELITIAN}

Didalam melakukan penelitian ini penulis menggunakan metode Deskriptif dan Asosiatif yaitu dengan melakukan studi kasus yang merupakan suatu metode yang bertujuan untuk mengamati aspek-aspek tertentu secara lebih spesifik untuk memperoleh data yang sesuai dengan tujuan penelitian. Dimana data tersebut diolah, dianalisis, dan diproses lebih lanjut dengan dasar teori-teori yang telah dipelajari sehingga dari data tersebut dapat ditarik suatu kesimpulan.

Sesuai dengan judul yang telah dikemukakan dan berdasarkan kepada identifikasi masalah yang ada maka objek yang dikaji dalam penelitian ini adalah pengaruh employee engagement yang disebut dengan variabel $\mathrm{X} 1$, komunikasi internal yang disebut dengan variabel $\mathrm{X} 2$, dan kinerja karyawan yang disebut dengan variabel $Y$.

Penelitian ini dilaksanakan pada Dealer Honda Auto Serang Banten. Penelitian ini dilakukan karena penulis ingin mengetahui bagaimana pengaruh employee engagement dan komunikasi internal terhadap kinerja karyawan pada Dealer Honda Auto Serang Banten.

Populasi adalah wilayah generalisasi yang terdiri atas obyek atau subyek yang mempunyai kualitas dan karakteristik tertentu yang ditetapkan oleh peneliti untuk dipelajari dan ditarik kesimpulannya. Populasi yang ditetapkan adalah karyawan di Dealer Honda Auto Serang Banten yang berjumlah 250 karyawan.

Sample menurut Sugiyono (2009:81) adalah bagian dari jumlah dan karakteristik yang dimiliki oleh populasi tersebut. Oleh karena itu dalam pengambilan sampel harus dilakukan dengan sangat hati-hati agar sampel yang digunakan dapat benar-benar mewakili populasi yang ada.

Sampel penelitian merupakan suatu faktor penting yang perlu diperhatikan dalam penelitian yang dilakukan. Sampel penelitian mencerminkan dan menentukan seberapa jauh sampel tersebut dimanfaatkan dalam membuat kesimpulan penelitian. Pengambilan sampel harus memenuhi syarat representative, artinya sampel yang diambil benar-benar mewakili populasi yang ada (representative).

Teknik pengambilan sampel yang digunakan adalah teknik pengambilan sampel secara acak (sample random sampling), dengan menggunakan rumusan slovin, Husein Umar (2004:108).

Dalam pengukuran data penelitian, penulis menggunakan skala pengukuran merupakan kesepakatan yang digunakan sebagai acuan untuk menentukan panjang pendek serta sedikit atau banyaknya varabel yang diteliti. 
Penelitian ini menggunakan skala pengukuran Skala Likert, yang dimana Sugiyono menjelaskan Skala Likert digunakan untuk mengukur sikap, pendapat dan persepsi seseorang atau sekelompok orang tentang fenomena sosial. Dalam skala ini akan dinyatakan dengan skor.

Tabel 1

Table Skala Likert

\begin{tabular}{|c|c|}
\hline Alternative Jawaban & Nilai Jawaban \\
\hline Sangat Setuju (SS) & 5 \\
\hline Setuju (S) & 4 \\
\hline Kurang Setuju (KS) & 3 \\
\hline Tidak Setuju (TS) & 2 \\
\hline Sangat Tidak Setuju (STS) & 1 \\
\hline
\end{tabular}

Dalam penelitian ini, setelah data terkumpul ataupun terakomodir, kemudian dilakukan analisis data, data-data yang telah diperoleh akan diolah dengan menggunakan teknik kuantitatif, yaitu pengolahan data yang berbentuk angka-angka dengan menggunakan rumus.

\section{HASIL DAN PEMBAHASAN}

\section{Uji Instrumen}

\section{Uji Validitas}

Tabel 2

Hasil Pengujian Validasi Variabel Xı (Employee Engagement)

\begin{tabular}{|c|c|c|c|}
\hline No & r hitung & r table & Keterangan \\
\hline 1 & 0,529 & 0,233 & Valid \\
\hline 2 & 0,546 & 0,233 & Valid \\
\hline 3 & 0,619 & 0,233 & Valid \\
\hline 4 & 0,602 & 0,233 & Valid \\
\hline 5 & 0,566 & 0,233 & Valid \\
\hline 6 & 0,444 & 0,233 & Valid \\
\hline 7 & 0,607 & 0,233 & Valid \\
\hline 8 & 0,758 & 0,233 & Valid \\
\hline 9 & 0,610 & 0,233 & Valid \\
\hline 10 & 0,639 & 0,233 & Valid \\
\hline 11 & 0,574 & 0,233 & Valid \\
\hline 12 & 0,450 & 0,233 & Valid \\
\hline
\end{tabular}


Berdasarkan pada tabel diatas, untuk nilai $\mathrm{r}$ tabel sebesar 0,233 dimana angka tersebut diperoleh dari signifikan 0,05 dengan uji dua sisi dan jumlah sampel sebanyak 71. Kemudian apabila hasil $r$ hitung keseluruhan item/instrumen dibandingkan dengan $\mathrm{r}$ tabel 0,233 maka dapat dinyatakan bahwa keseluruhan item adalah valid karena hasil nilai $r$ hitung lebih besar dari $r$ tabel.

Tabel 3

Hasil Pengujian Validasi Variabel $\mathbf{X}_{2}$ (Komunikasi Internal)

\begin{tabular}{|c|c|c|c|}
\hline No & r hitung & r tabel & Keterangan \\
\hline 1 & 0,619 & 0,233 & Valid \\
\hline 2 & 0,703 & 0,233 & Valid \\
\hline 3 & 0,661 & 0,233 & Valid \\
\hline 4 & 0,664 & 0,233 & Valid \\
\hline 5 & 0,667 & 0,233 & Valid \\
\hline 6 & 0,605 & 0,233 & Valid \\
\hline 7 & 0,616 & 0,233 & Valid \\
\hline 8 & 0,508 & 0,233 & Valid \\
\hline 9 & 0,530 & 0,233 & Valid \\
\hline 10 & 0,617 & 0,233 & Valid \\
\hline 11 & 0,646 & 0,233 & Valid \\
\hline 12 & 0,653 & 0,233 & Valid \\
\hline 13 & 0,487 & 0,233 & Valid \\
\hline 14 & 0,640 & 0,233 & Valid \\
\hline 15 & 0,613 & 0,233 & Valid \\
\hline
\end{tabular}

Berdasarkan pada tabel diatas, untuk nilai $\mathrm{r}$ tabel sebesar 0,233 dimana angka tersebut diperoleh dari signifikan 0,05 dengan uji dua sisi dan jumlah sampel sebanyak 71. Kemudian apabila hasil $r$ hitung keseluruhan item/instrumen dibandingkan dengan $\mathrm{r}$ tabel 0,233 maka dapat dinyatakan bahwa keseluruhan item adalah valid karena hasil nilai $r$ hitung lebih besar dari $r$ tabel.

Tabel 4

Hasil Pengujian Validasi Variabel Y (Kinerja Karyawan)

\begin{tabular}{|c|c|c|c|}
\hline No & r hitung & r tabel & Keterangan \\
\hline 1 & 0,706 & 0,233 & Valid \\
\hline 2 & 0,683 & 0,233 & Valid \\
\hline 3 & 0,663 & 0,233 & Valid \\
\hline 4 & 0,741 & 0,233 & Valid \\
\hline 5 & 0,600 & 0,233 & Valid \\
\hline
\end{tabular}




\begin{tabular}{|c|c|c|c|}
\hline 6 & 0,707 & 0,233 & Valid \\
\hline 7 & 0,621 & 0,233 & Valid \\
\hline 8 & 0,380 & 0,233 & Valid \\
\hline 9 & 0,723 & 0,233 & Valid \\
\hline 10 & 0,661 & 0,233 & Valid \\
\hline
\end{tabular}

Pada hasil data diatas menunjukkan bahwa $r$ hitung secara keseluruhan lebih besar jika dibandingkan dengan $\mathrm{r}$ tabel. Maka dapat disimpulkan bahwa untuk keseluruhan item/instrumen pada uji validitas Kinerja Karyawan dinyatakan Valid.

\section{Uji Reliabilitas}

Tabel 5

Perbandingan Nilai Uji Reliabilitas

\begin{tabular}{|c|c|c|c|}
\hline Variabel & $\begin{array}{c}\text { Nilai } \\
\text { Cronbach's } \\
\text { Alpha }\end{array}$ & $\begin{array}{c}\text { Perbandingan } \\
\text { pada Scale of } \\
\text { thumb, } \\
\text { nunnually }\end{array}$ & Kesimpulan \\
\hline $\begin{array}{c}\text { Employee Engagement } \\
(\mathrm{X} 1)\end{array}$ & 0,817 & 0,60 & Reliabel \\
\hline $\begin{array}{c}\text { Komunikasi Internal } \\
(\mathrm{X} 2)\end{array}$ & 0,882 & 0,60 & Reliabel \\
\hline Kinerja Karyawan (Y) & 0,846 & 0,60 & Reliabel \\
\hline
\end{tabular}

Dapat disimpulkan bahwa dari ketiga variabel yang diuji tersebut memiliki nilai Cronbach's Alpha diatas ketentuan scale of thumb nunnually dengan $\alpha=$ 0,60 , maka seluruh instrumen dikatakan reliabel. 


\section{Uji Asumsi Klasik Regresi}

\section{Uji Normalitas}

Tabel 9

Hasil Uji Normalitas

One-Sample Kolmogorov-Smirnov Test

\begin{tabular}{|ll|r|r|r|}
\hline & & $\begin{array}{r}\text { Employee } \\
\text { Engageme } \\
\text { nt }\end{array}$ & $\begin{array}{c}\text { Komunik } \\
\text { asi } \\
\text { Internal }\end{array}$ & $\begin{array}{c}\text { Kinerja } \\
\text { Karyaw } \\
\text { an }\end{array}$ \\
\hline $\mathrm{N}$ & 71 & 71 & 71 \\
Normal Parameters $^{\mathrm{a}, \mathrm{b}}$ & Mean & 50,52 & 63,20 & 44,94 \\
& Std. & 4,074 & 5,502 & 2,883 \\
Most Extreme & Deviation &, 099 &, 100 &, 102 \\
Differences & Absolute &, 098 &, 100 &, 102 \\
& Positive &,- 099 &,- 083 &,- 075 \\
Test Statistic & Negative &, 099 &, 100 &, 102 \\
Asymp. Sig. (2-tailed) &, $082^{\mathrm{c}}$ &, $077^{\mathrm{c}}$ &, $064^{\mathrm{c}}$ \\
\hline
\end{tabular}
a. Test distribution is Normal.
b. Calculated from data.
c. Lilliefors Significance Correction.

Berdasarkan tabel One-Sample Kolmogorov-Smirnov Test diatas dapat diketahui nilai Kolmogorov-Smirnov sebesar 0,099 (Employee Engagement), 0,100 (Komunikasi Internal), dan 0,102 (Kinerja Karyawan). Karena nilai statistik Kolmogorov-Smirnov $>$ taraf signifikan $(\alpha)$ 0,05 hasilnya adalah 0,099 (X1), $0,100(\mathrm{X} 2)$, dan 0,102 (Y) > 0,05 dapat disimpulkan yaitu nilai residual dari uji normalitas secara normal karena nilai signifikansinya lebih besar dari 5\% maka uji asumsi klasik normalitas terpenuhi atau berdistribusi normal.

Sedangkan untuk kurva uji normalitas dengan menggunakan grafik histogram adalah sebagai berikut : 


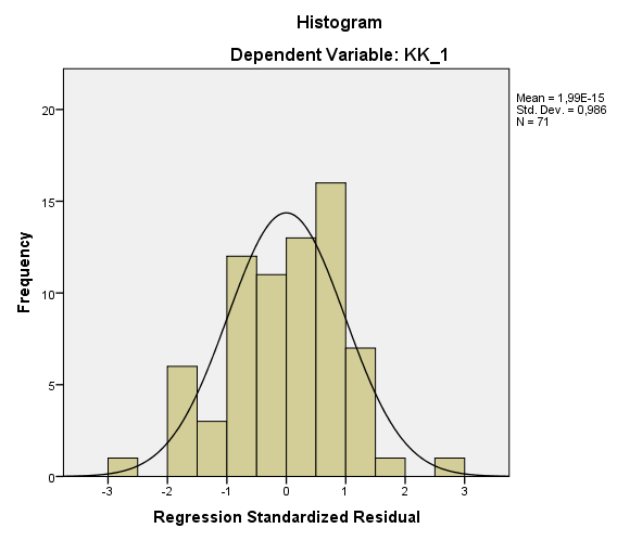

Gambar 2

Grafik Histogram

Dengan melihat kurva hitogram dapat dikatakan bahwa model berdistribusi normal karena kurva berbentuk lonceng. Pada diagram Normal Probability Plot terlihat titik-titik yang menyebar yang kesemuanya menunjukkan bahwa model berdistribusi normal.

\section{Uji Multikolinearitas}

Tabel 10

Uji Multikolinearitas

Coefficients $^{\mathrm{a}}$

\begin{tabular}{|c|c|c|c|c|c|c|c|}
\hline \multirow[b]{2}{*}{ Model } & \multicolumn{2}{|c|}{$\begin{array}{l}\text { Unstandardi } \\
\text { zed } \\
\text { Coefficients }\end{array}$} & \multirow{2}{*}{$\begin{array}{c}\text { Standardize } \\
\mathrm{d} \\
\text { Coefficient } \\
\mathrm{s} \\
\\
\text { Beta }\end{array}$} & \multirow[b]{2}{*}{$\mathrm{t}$} & \multirow[b]{2}{*}{ Sig. } & \multicolumn{2}{|c|}{$\begin{array}{c}\text { Collinearity } \\
\text { Statistics }\end{array}$} \\
\hline & B & $\begin{array}{l}\text { Std. } \\
\text { Error }\end{array}$ & & & & $\begin{array}{c}\text { Toleranc } \\
\mathrm{e}\end{array}$ & VIF \\
\hline 1 (Constant) & 5,521 & $\overline{3,461}$ & & 1,595 &, 115 & & \\
\hline $\begin{array}{l}\text { Employee } \\
\text { Engagement }\end{array}$ & ,334 & ,094 & 370 & 3,544 &, 001 & ,489 & 2,047 \\
\hline $\begin{array}{l}\text { Komunikasi } \\
\text { Internal }\end{array}$ & ,322 & ,069 & ,490 & 4,692 &, 000 & ,489 & 2,047 \\
\hline
\end{tabular}

a. Dependent Variable: Kinerja Karyawan

Dari tabel diatas dapat dilihat bahwa nilai Tolerance diperoleh 0,489 dan nilai Variance Inflation Factor (VIF) diperoleh 2,047 hasil keputusan untuk uji multikolinearitas adalah jika nilai Tolerance > 0,10 dan Variance Inflation Factor (VIF) $<10,00$ mencerminkan tidak ada multikolinearitas. 


\section{Uji Heteroskedastisitas}

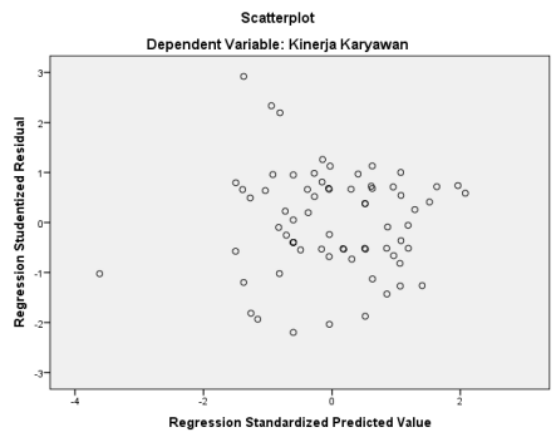

Gambar 3

\section{Uji Heteroskedastisitas}

Melihat dari grafik Scatterplot terlihat bahwa titik-titik menyebar secara acak serta tersebar baik diatas maupun dibawah angka 0 (nol) pada sumbu Y maka dapat disimpulkan bahwa dalam model regresi yang digunakan tidak terjadi heteroskedastisitas pada penelitian.

\section{Analisis Regresi Linier Berganda}

\section{Tabel 11}

Uji Analisis Regresi Linier Berganda

Pengaruh Employee Engagement $\left(\mathrm{X}_{\mathrm{I}}\right)$ dan Komunikasi Internal $\left(\mathrm{X}_{2}\right)$ terhadap Kinerja Karyawan (Y)

Coefficients $^{\mathrm{a}}$

\begin{tabular}{|c|c|c|c|c|c|}
\hline \multirow[b]{2}{*}{ Model } & \multicolumn{2}{|c|}{$\begin{array}{c}\text { Unstandardized } \\
\text { Coefficients }\end{array}$} & $\begin{array}{c}\text { Standardize } \\
\mathrm{d} \\
\text { Coefficient } \\
\mathrm{s}\end{array}$ & \multirow[b]{2}{*}{$\mathrm{t}$} & \multirow[b]{2}{*}{ Sig. } \\
\hline & B & $\begin{array}{l}\text { Std. } \\
\text { Error }\end{array}$ & Beta & & \\
\hline $1 \quad$ (Constant $)$ & 5,521 & 3,461 & & 1,595 &, 115 \\
\hline Employee & 334 & 094 & & 3544 & 001 \\
\hline Engagement & ,334 & ,094 &, $3 / 0$ & 3,544 & , 001 \\
\hline Komunikasi Internal & ,322 & 069 & ,490 & 4,692 & ,000 \\
\hline
\end{tabular}

a. Dependent Variable: Kinerja Karyawan

Berdasarkan tabel diatas, maka dapat dibentuk persamaan regresi sebagai berikut :

$$
\begin{aligned}
& Y=a+b_{1} X_{1}+b_{2} X_{2} \\
& Y=5,521+0,334 X_{1}+0,322 X_{2}
\end{aligned}
$$


Berdasarkan persamaan garis regresi yang diperoleh, maka model regresi tersebut diinterpretasikan sebagai berikut :

a. Koefisien konstanta $=5,521$ hal ini berarti bahwa apabila nilai dari Employee Engagement $\left(\mathrm{X}_{1}\right)$ dan Komunikasi Internal $\left(\mathrm{X}_{2}\right)$ sama dengan nol, maka tingkat atau besarnya Kinerja Karyawan (Y) sebesar 5,521\%.

b. Koefisien $b_{1}=0,334$ hal ini berarti bahwa apabila nilai $\mathrm{X}_{1}$ (Employee Engagement) mengalami kenaikan sebesar 1\%, sementara variabel independen lainnya bersifat tetap, maka tingkat variabel $\mathrm{Y}$ (Kinerja Karyawan) akan mengalami kenaikan sebesar 0,334\%.

c. Koefisien $b_{2}=0,322$ hal ini berarti bahwa apabila nilai $\mathrm{X}_{2}$ (Komunikasi Internal) mengalami kenaikan sebesar $1 \%$, sementara variabel independen lainnya bersifat tetap, maka tingkat variabel Y (Kinerja Karyawan) akan mengalami kenaikan sebesar $0,322 \%$.

\section{Koefisien Determinansi}

Tabel 12

Uji Koefisien Determinansi

Model Summary

\begin{tabular}{|l|l|r|r|r|}
\hline Model & $\mathrm{R}$ & R Square & $\begin{array}{c}\text { Adjusted R } \\
\text { Square }\end{array}$ & $\begin{array}{c}\text { Std. Error of } \\
\text { the Estimate }\end{array}$ \\
\hline 1 &, $798^{\mathrm{a}}$ &, 637 &, 627 & 2,24453 \\
\hline
\end{tabular}

a. Predictors: (Constant), Komunikasi Internal, Employee

Engagement

Dari perhitungan diatas diperoleh nilai koefisien determinansi berganda $\left(\mathrm{R}^{2}\right)$ Adjusted $R$ Square sebesar 0,627. Hal ini dapat diartikan bahwa besarnya kontribusi Employee Engagement (X1) dan Komunikasi Internal ( $\left.\mathrm{X}_{2}\right)$ mempengaruhi sebesar $62,7 \%$ terhadap Kinerja Karyawan (Y) sedangkan sisanya sebesar 37,3\%. Guna dari Adjusted $R$ Square yaitu untuk menggenerealisasikan $R$ Square pada populasi, karena ada unsur estimasi populasi didalamnya, seperti pengambilan melalui random dari populasi yang ditetapkan. 


\section{Uji T}

\section{Pengujian Hipotesis 1}

\section{Tabel 13}

Uji t

Variabel Employee Engagement (X) dan Kinerja Karyawan (Y)

Coefficients $^{\mathrm{a}}$

\begin{tabular}{|c|c|c|c|c|c|}
\hline \multirow[b]{2}{*}{ Model } & \multicolumn{2}{|c|}{$\begin{array}{c}\text { Unstandardized } \\
\text { Coefficients }\end{array}$} & \multirow{2}{*}{$\begin{array}{c}\text { Standardize } \\
\mathrm{d} \\
\text { Coefficient } \\
\mathrm{s} \\
\text { Beta }\end{array}$} & \multirow[b]{2}{*}{$\mathrm{t}$} & \multirow[b]{2}{*}{ Sig. } \\
\hline & $\mathrm{B}$ & $\begin{array}{l}\text { Std. } \\
\text { Error }\end{array}$ & & & \\
\hline $\begin{array}{ll}1 & \text { (Constant) }\end{array}$ & $\overline{5,521}$ & 3,461 & & 1,595 &, 115 \\
\hline $\begin{array}{l}\text { Employee } \\
\text { Engagement }\end{array}$ & ,334 & ,094 & ,370 & 3,544 &, 001 \\
\hline Komunikasi Internal & ,322 & ,069 &, 490 & 4,692 & 000 \\
\hline
\end{tabular}

a. Dependent Variable: Kinerja Karyawan

Berdasarkan hasil output diatas, maka dapat diketahui apakah sebenarnya Employee Engagement mempunyai pengaruh terhadap Kinerja Karyawan, dan hasil perhitungan yang didapat adalah ttabel $=\mathrm{t}(\alpha / 2 ; \mathrm{n}-\mathrm{k}-1)=\mathrm{t}(0,025 ; 68)=$ 1,995 sedangkan thitung sebesar 3,544 maka Employee Engagement ( $\left.\mathrm{X}_{1}\right)$ terhadap Kinerja Karyawan (Y) dalam uji t, didapat hasil thitung > ttabel $(3,544>1,997)$ dengan tingkat signifikansi sebesar 0,001 $(0,001<0,05)$ maka dapat disimpulkan bahwa terdapat pengaruh yang signifikan antara Employee Engagement terhadap Kinerja Karyawan pada Dealer Honda Auto Serang Banten.

\section{Pengujian Hipotesis 2}

\section{Tabel 14}

Uji t

\section{Variabel Komunikasi Internal $\left(\mathrm{X}_{2}\right)$ dan Kinerja Karyawan (Y)}

Coefficients $^{\mathbf{a}}$

\begin{tabular}{|c|c|c|c|c|c|}
\hline & $\begin{array}{r}\text { Uns } \\
\mathrm{C}(\end{array}$ & $\begin{array}{l}\text { lardized } \\
\text { cients }\end{array}$ & $\begin{array}{c}\text { Standardize } \\
\mathrm{d} \\
\text { Coefficient } \\
\mathrm{s}\end{array}$ & & \\
\hline Model & B & $\begin{array}{l}\text { Std. } \\
\text { Error }\end{array}$ & Beta & $\mathrm{t}$ & Sig. \\
\hline
\end{tabular}




\begin{tabular}{|ll|r|r|r|r|r|}
\hline 1 & (Constant) & 5,521 & 3,461 & & 1,595 &, 115 \\
& Employee &, 334 &, 094 &, 370 & 3,544 &, 001 \\
& Engagement & & & & \\
& Komunikasi Internal &, 322 &, 069 &, 490 & 4,692 &, 000 \\
\hline
\end{tabular}

a. Dependent Variable: Kinerja Karyawan

Berdasarkan hasil output diatas, maka dapat diketahui apakah sebenarnya komunikasi internal mempunyai pengaruh terhadap kinerja karyawan, dan hasil perhitungan yang didapat adalah ttabel $=\mathrm{t}(\alpha / 2 ; \mathrm{n}-\mathrm{k}-1)=\mathrm{t}(0,025 ; 68)=1,995$ sedangkan thitung sebesar 4,692 maka Komunikasi Internal $\left(\mathrm{X}_{2}\right)$ terhadap Kinerja Karyawan (Y) dalam uji t, didapat hasil thitung > ttabel $(4,692>1,997)$ dengan tingkat signifikansi sebesar 0,000 $(0,000<0,05)$ maka dapat disimpulkan bahwa terdapat pengaruh yang signifikan antara Komunikasi Internal terhadap Kinerja Karyawan pada Dealer Honda Auto Serang Banten.

\section{Uji F}

\section{Pengujian Hiotesis 3}

\section{Tabel 15 \\ Uji F}

\begin{tabular}{|c|c|c|c|c|c|c|}
\hline \multicolumn{7}{|c|}{ ANOVA $^{\mathrm{a}}$} \\
\hline \multicolumn{2}{|c|}{ Model } & $\begin{array}{l}\text { Sum of } \\
\text { Squares }\end{array}$ & df & $\begin{array}{l}\text { Mean } \\
\text { Square }\end{array}$ & $\mathrm{F}$ & Sig. \\
\hline \multirow[t]{3}{*}{1} & Regression & 601,620 & 2 & 300,810 & 59,709 &, $000^{\mathrm{b}}$ \\
\hline & Residual & 342,577 & 68 & 5,038 & & \\
\hline & Total & 944,197 & 70 & & & \\
\hline
\end{tabular}

a. Dependent Variable: Kinerja Karyawan

b. Predictors: (Constant), Komunikasi Internal, Employee

Engagement

Setelah pengujian dilakukan diperoleh Fhitung $=59,709$ sedangkan nilai Ftabel $=\mathrm{F}(\mathrm{k} ; \mathrm{n}-\mathrm{k})=\mathrm{F}(2 ; 69)=3,13$ dengan taraf nyata sebesar 0,05 . Fhitung > Ftabel $(59,709>3,13)$ dengan demikian $\mathrm{H} 0$ ditolak dan $\mathrm{H}_{1}$ diterima yang berarti terdapat pengaruh yang signifikan antara Employee Engagement dan Komunikasi Internal terhadap Kinerja Karyawan Dealer Honda Auto Serang Banten. 


\section{KESIMPULN DAN SARAN}

\section{Kesimpulan}

Berdasarkan analisis data yang telah dilakukan dan pembahasan yang telah dikemukakan pada bab sebelumnya, dapat ditarik beberapa kesimpulan, yaitu :

1. Terdapat pengaruh yang signifikan antara Employee Engagement terhadap Kinerja Karyawan pada Dealer Honda Auto Serang Banten. Employee Engagement pada Dealer Honda Auto Serang Banten tergolong dalam kategori baik yang ditunjukkan dengan nilai skala tanggapan responden total skor rata-rata yang didapat adalah sebesar 300 berada pada interval 245-302 yang masuk dalam kategori baik.

2. Terdapat pengaruh yang signifikan antara Komunikasi Internal terhadap Kinerja Karyawan pada Dealer Honda Auto Serang Banten. Komunikasi Internal pada Dealer Honda Auto Serang Banten tergolong dalam kategori baik yang ditunjukkan dengan nilai skala tanggapan responden total skor ratarata yang didapat adalah sebesar 290 berada pada interval 245-302 yang masuk dalam kategori baik.

3. Terdapat pengaruh yang signifikan antara Employee Engagement $\left(\mathrm{X}_{1}\right)$ dan Komunikasi Internal $\left(\mathrm{X}_{2}\right)$ terhadap variabel dependen yaitu Kinerja Karyawan (Y) pada Dealer Honda Auto Serang Banten. Besarnya pengaruh kedua variabel independen diperoleh nilai Adjusted $R$ Square sebesar 0,627 atau $62,7 \%$, ini menunjukkan bahwa variabel kinerja karyawan yang dapat dijelaskan oleh variabel employee engagementdan komunikasi internal adalah sebesar $62,7 \%$. Sedangkan sisanya 37,3\% dipengaruhi variabel lain.

\section{Saran}

Berdasarkan hasil penelitian ini dapat disampaikan beberapa saran sebagai berikut :

1. Berdasarkan hasil tanggapan responden bahwa untuk item yang terkecil terdapat pada pertanyaan nomor 12 variabel Employee Engagement tentang bagaimana karyawan menikmati pekerjaan sehingga lupa akan hal-hal lain, yang berarti karyawan kurang bisa menikmati pekerjaannya. Oleh karena itu selayaknya pihak manajemen perusahaan memperhatikan hal tersebut sehingga karyawan bisa lebih menikmati pekerjaan yang diberikan atasan kepada karyawan tersebut agar pekerjaan bisa terselesaikan dengan baik dan tepat waktu.

2. Mayoritas karyawan memiliki penilaian yang positif "baik" mengenai variabel employee engagement dan variabel komunikasi internal. Oleh karena itu, sangat penting bagi perusahaan untuk terus menjaga keterikatan dengan karyawan dan komunikasi yang terjadi didalam perusahaan, agar para karyawan terus termotivasi untuk meningkatkan kinerjanya. 
3. Bagi peneliti selanjutnya, diharapkan hasil penelitian ini dapat menjadi bahan referensi atau literature penelitian lebih lanjut yang berhubungan dengan Employee Engagemehant dan Komunikasi Internal terhadap Kinerja Karyawan. Diharapkan lebih luas dan menemukan variabel lain, contohnya motivasi, kepuasan, dan lain-lain yang dapat mempengaruhi dan meningkatkan kinerja karyawan didalam suatu organisasi/perusahaan.

\section{DAFTAR PUSTAKA}

\section{Jurnal}

Agnes Wahyu Handoyo dan Roy Setiawan, (2017) Pengaruh Employee Engagement Terhadap Kinerja Karyawan pada PT. Tirta Rejeki Dewata. : AGORA, [online] Vol. 5, No.1. Tersedia : http://media.neliti.com/ [19 November 2018 - 17.20].

Debby Siswono, Sim (2016) Pengaruh Employee Engagement Terhadap Kinerja Karyawan Di Rodex Travel Surabaya. : AGORA [online] Vol. 4, No.2.

Tersedia : http://publication.petra.ac.id/ [28 November 2018 - 22.08].

Devi Novitasari dan Rony Ika Setiawan, (2015) Pengaruh Komunikasi Internal,

Pelatihan Kerja Dan Kemampuan Kerja Terhadap Kinerja Karyawan Pada

CV Tirto Agung Lodoyo. : ISSN: 2407-2680 [online] Riset Mahasiswa

Ekonomi (RITMIK) Vol. 2, No.1. Tersedia : http://repository.stieken.ac.id/ [7 Desember 2018 - 07.29].

Gita Lestari dan Kasmirudin, (2017) Pengaruh Komunikasi Internal Dan Motivasi

Kerja Terhadap Kinerja Karyawan Industri Media PT. Riau Media Televisi (Rtv) Pekanbaru. : JOM FISIP [online] Vol. 4, No.2 - Oktober 2017. Tersedia : http://media.neliti.com/ [19 November 2018 - 21.54].

Nabilah Ramadhan dan Jafar Sembiring, (2014) Pengaruh Employee Engagement

Terhadap Kinerja Karyawan Di Human Capital Center PT.

Telekomunikasi Indonesia, Tbk. : JURNAL MANAJEMEN INDONESIA [online] Vol. 14, No.1 - April 2014. Tersedia : http://scholar.google.co.id/ [28 November 2018 - 22.08].

Niken Dwi Ardila dan Hengky Pramusinto, (2015) Pengaruh Kepemimpinan, Komunikasi Internal, dan Motivasi Kerja Terhadap Kinerja Pegawai BP3AKB Provinsi Jawa Tengah. : JURNAL PENDIDIKAN EKONOMI DINAMIKA PENDIDIKAN [online] Vo. X No.1 Juni 2015. Tersedia : http://media.neliti.com/ [29 Desember 2018 - 18.05].

Okta Fitri Fauzi dan Dr. Jafar Sembiring M.Ed.M, (2016) Pengaruh Employee Engagement Terhadap Kinerja Karyawan Di PT Studio Cilaki Empat Lima Bandung. : ISSN : 2355-9357 [online] e-Proceeding of Management 
: Vol. 3, No.3 December 2016 | Page 3080. Tersedia : http://openlibrary.telkomuniversity.ac.id/ [3 Desember 2018 - 17.30].

Raka Febrian, Reni Nuraeni, S.Sos., M.Si, dan Agus Aprianti, S.I.Kom., M.I.Kom, (2016) Pengaruh Komunikasi Internal Terhadap Kinerja Karyawan (Studi pada Hotel Horison Ultima Bandung bagian Room Division). : ISSN : 2355-9357 [online] e-Proceeding of Management : Vol. 3, No.2 Agustus $2016 \quad$ Page 2447. Tersedia : http://openlibrary.telekomuniversity.ac.id/ [7 Desember 2018 - 07.29].

Untung Sriwidodo dan Agus Budhi Haryanto, (2010) Pengaruh Kompetensi, Motivasi, Komunikasi dan Kesejahteraan Terhadap Kinerja Pegawai Dinas Pendidikan. : Jurnal manajemen Sumberdaya Manusia [online] Vol. 4, No.1 Juni 2010: 47-57. Tersedia : http://scholar.google.co.id/ [17 November 2018 - 18.13].

Yudi Muliawan, Badia Perizade, dan Afriyadi Cahyadi, (2017) Pengaruh

Keterikatan Karyawan (Employee Engagement) Terhadap Kinerja Karyawan Di PT. Badja Baru Palembang. : JEMBATAN - Jurnal Ilmiah Manajemen Bisnis Dan Terapan Tahun XIV [online] No.2, Oktober 2017. Tersedia : http://ejournal.unsri.ac.id/ [29 Desember 2018 - 18.00].

Keterikatan Karyawan (Employee Engagement) - Kajian Pustaka.com [online]. Tersedia : http://www.kajianpustaka.com/ [28 Desember 2018 - 07.10]. 